\title{
Do Amateur Sellers Adopt The Professionals' Price Ending Formats? Lessons From The Used Car Market
}

\author{
Marc Prieto, ESSCA School of Management, L’UNAM Université, France
}

\begin{abstract}
This study investigates the differences between professional retailers and amateur resellers in their adoption of different price ending formats. We conduct our analysis on a 1,700 ads car pool representative of the French used car market to demonstrate how seller profiles and car attributes impact price ending formats adoption. The results reveal that amateur sellers are more likely to use round ending prices than professionals, especially for expensive and high mileage cars. Furthermore, product attributes (extras) and obsolescence indicators significantly moderate the choices of price ending formats.
\end{abstract}

Keywords: Price Ending Formats; Second-Hand Markets; Disposition Behavior; Discrete Choice Models

\section{INTRODUCTION}

$\mathrm{t}$ is well known that some prices appear more often in retailing practice than others (Bader \& Weinland, 1932; Rudolph, 1954). Research into these uses continues in social science and marketing streams (Nagle et al., 2011; Schindler, 2011), with a predominant focus on how 9-ending prices create a low
price appeal (Schindler, 2006) and exert positive impacts on sales (Anderson \& Simister, 2003; Bray \& Harris, 2006; Macé, 2012; Manning \& Sprott, 2009; Ngobo et al., 2010; Schindler \& Kibarian, 1996; Twedt, 1965, Wagner $\&$ Beinke, 2006). Many of these studies address traditional retail contexts and new items.

However, transactions of used items constitute growing markets for various durable goods, such as clothing, vehicles, informatics, and electronics. These used item transactions also appear in various distribution channels, especially facilitated by the rise of the Internet. Used goods markets for durable products (Williams \& Paddock, 2003; Yin et al., 2010), and in particular the second hand car market, increase in terms of transaction volume and value (Trend Tracker, 2009). Despite market saturation as well as the economic crisis spreading across Europe, the car park is still growing especially because of second hand transactions (European Automobile Manufacturer's Association, ACEA, 2012). In France, used cars registrations represent approximately three times more than new car registrations in 2012. In the 1990's, this ratio was around two (French Automobile Manufacturer's Association, CCFA, 2012). These trends confirm the importance of used car market in the economy and demand a better understanding for car manufacturers and retailers.

These second hand markets also reflect disposition behavior theory, which addresses the factors that enable people to dispense of items by transferring their ownership to others (Boyd \& McConocha, 1996). Although this literature considers the main channels consumers use to dispose of unwanted goods (Harell \& McConocha, 1992; Jacoby et al., 1977), redistribution choices remain insufficiently investigated (Paden \& Stell, 2005). In particular, the price ending formats that are most common in redistribution channels are unknown, even though the attractiveness of pricing for used items likely has significant implications. Therefore, as the used car market is very important in European economies, the current study proposes an exploratory research applied to the price ending formats adopted in redistribution used car channels. The analysis focuses on ending prices formats employed by two main sellers in second-hand car markets, namely, professional retailers and amateur individual sellers. The first objective is to define the most frequently price ending formats fixed by these two types of sellers as well as if these formats are common or not. Secondly, we evaluate the correlation between the adoption of such formats and several explanatory variables. 


\section{RESEARCH BACKGROUND}

Disposition is "a process of getting rid of an item by transferring product ownership or responsibility to another household or organization" (Paden \& Stell, 2005, p. 107), and it can occur through formal or informal channels. The success of disposition practices has been reinforced by the use of the Internet, especially through auction and classified ad websites (Roux \& Guiot, 2008). According to research into the main channels that consumers use to dispose of their unwanted goods (Boyd \& McConocha, 1996; Harell \& McConocha, 1992; Jacoby et al., 1977), they provide the good either directly to another consumer (e.g., classified ads, garage sales) or indirectly through a sale to professional retailers (e.g., consignment, auctions). Consumers likely develop different perceptions of these channels. As Holbrook (1999) notes, consumers may value the purchase of used items and avoid traditional retailers, in which case they likely prefer to buy directly from an individual seller (C2C), in search of good deals. Yet the $\mathrm{C} 2 \mathrm{C}$ channel also allows consumers to avoid stressful bargaining with sales representatives, whom many consumers regard as less than honest (Grover \& Enz, 2005). Trust in salespersons (Wood et al., 2008) is particularly important for high-involvement purchases (e.g., residences, cars, home repairs; Hawkins et al., 2004). Yet despite practical and theoretical interest in disposition behavior, marketing literature has granted it only limited attention, especially in terms of channel choices (Paden \& Stell, 2005). Little is known about the pricing tactics used by different seller types in second-hand markets either, even if price ending formats choice is a central strategic tactic for virtually any sale (Schindler, 2011). Cultural context helps determine the influences of price endings (Nguyen et al., 2007), though the numbers 0, 5, and 9 are the most frequent values used for the rightmost digit of a price. That is, the distribution of prices is not uniform across numerals (Folkertsma, 2002; Schindler \& Kirby, 1997). Aalto-Setala and Halonen (2004) reveal that it is not only the rightmost digit that is non-uniformly distributed; their proposed price setting model includes all price digits, including those for used items. Their study represents an exception though, in that most research focuses on 9-ending prices and their rationales, based on level and image effects (Stiving \& Winer, 1997).

As we mentioned above, very little attention has been given to this topic in the marketing literature despite the recent growth in used product transactions. Regarding the disposition of unwanted used goods, such price endings also likely appear in various redistribution channels. The paper addresses this question considering the used car market. The following section describes the methodology and the data of the study.

\section{METHODOLOGY AND DATA}

\section{Research Questions and Methodology}

Previous empirical studies concerning price ending formats show that retailers use certain prices much more frequently than others. The distribution of digits has been demonstrated to be not uniformly distributed in the special case of the used car market (Aalto \& Setala, 2004). But, used good transactions are concluded by retailers as well as individuals (who sell their unwanted goods). This special situation leads us to question how these two types of resellers define their price ending formats. To do so, the empirical analysis relies on used car markets, as a traditional form of used marketplaces (Akerlof, 1970) and because consumers are highly involved in buying automobiles (Hawkins et al., 2004). Over a two-month period in 2011, a representative sample of 1,700 car ads was drawn from the most popular used car sale website in France, "leboncoin.fr." To ensure representativeness, the sampling quotas reflected insights gained from the French Consumer Survey by the National French Institute of Statistics (INSEE, Enquête Budget de Familles, 2006) and national car registration data provided by the French Car Manufacturer Association (CCFA, 2012). This procedure produced an overall sample with the distribution detailed in Table 1.

Table 1: Sample Profile

\begin{tabular}{lcccc}
\hline \multirow{2}{*}{ Car Age } & \multicolumn{2}{c}{ Age: Less than Five Years } & \multicolumn{2}{c}{ Age: More than Five Years } \\
\cline { 2 - 5 } & Professional & Individual & Professional & Individual \\
\hline \multirow{2}{*}{ Diesel } & 403 & 126 & 167 & 315 \\
& $(23.7 \%)$ & $(7.4 \%)$ & $(9.8 \%)$ & $(18.5 \%)$ \\
\hline \multirow{2}{*}{ Petrol } & 131 & 63 & 167 & 328 \\
& $(7.7 \%)$ & $(3.7 \%)$ & $(9.8 \%)$ & $(19.3 \%)$ \\
\hline
\end{tabular}


Firstly, we investigate the most commonly price ending formats used by both types of resellers. We focus on the potential differences that could exist between price ending formats adoption for these two seller' profiles. This objective is formulated in the following research question:

RQ1: Do amateur and professional car resellers use similar price ending formats?

This study also relies on previous literature related to the information perspective (Stiving \& Winer, 1997), which indicates that prices convey quality, image, and attractiveness information to buyers. Consistent with theory from information economics (Akerlof, 1970; Milgrom \& Roberts, 1986), the price presentation is part of the information offered to potential buyers who face information asymmetry about product quality or value. Therefore, they infer information from existing signals (Spence, 1973), including the format of ending prices. To understand these signals in the special used car market, we investigate the relation between price ending formats adoption and car attributes. The objective is to identify the car attributes that are mainly observed for each type of price ending format. In this perspective, we also investigate the seller's type impact on pricing adoption considering interaction with car attributes.

RQ2: Is the adoption of price ending formats driven by car attributes or/and by seller's type?

The next section describes more precisely the used car price data collected for the study and defines the price ending formats.

\section{Data}

The website provided 868 ads posted by individual sellers and 867 ads posted by professional sellers, with the distribution of asking prices indicated by Figure 1. The majority of prices $(64.73 \%)$ are less than 10,000 Euros, so this study investigates used car price endings that signal values of hundreds, tens, and ones. We focus on the three rightmost digits of used car prices as potential signals associated to thousands.

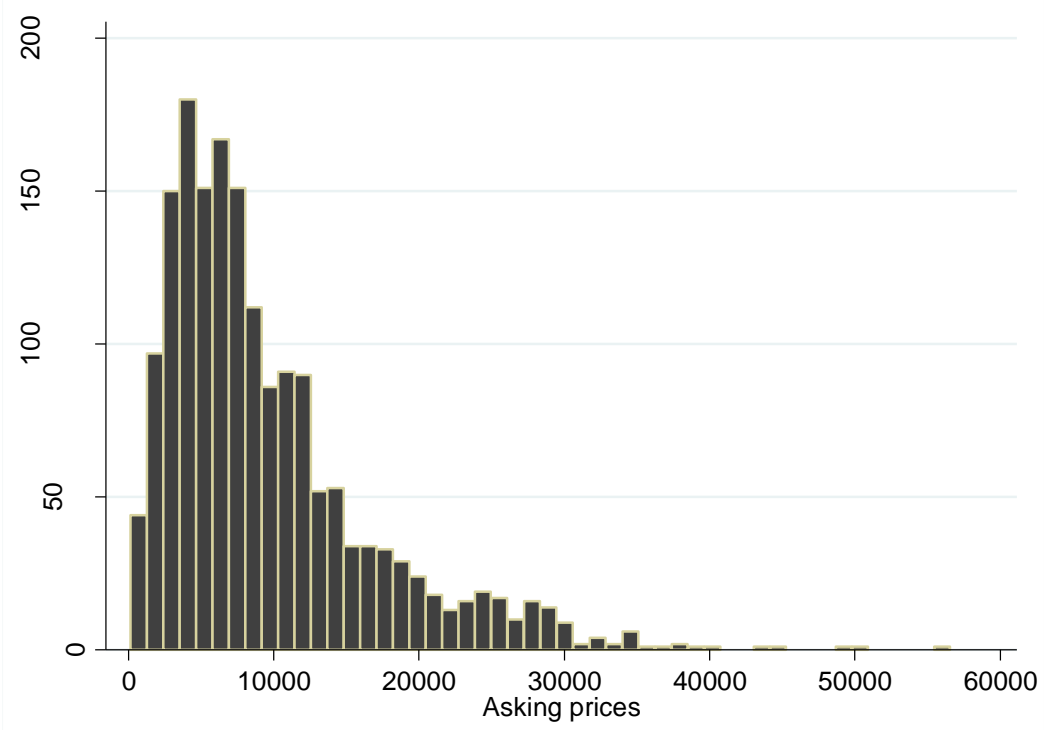

Figure 1: Asking Price Distribution

The collected car ads offer additional information about the asking price, car attributes (e.g., engine type, engine power, mileage, age), and the presence of extras (e.g., air conditioning, GPS). A preliminary analysis reveals that 9 is the most often used digit in the third position from the right (i.e., hundreds value), followed by 5 and 0 (e.g., $€ X, 9 X X ; € X, 5 X X ; € X, 0 X X)$. In the second position (tens), 0 is used most frequently, followed by 9 and 5 (€X,X0X; $€ X, X 9 X ; € X, X 5 X)$; this same pattern holds for the rightmost position (i.e., ones: $€ X, X X 0 ; € X, X X 9$; $€ X, X X 5$ ). Table 2 contains a more detailed review. 
Table 2: Distribution (\%) of Digits in Used Car Ads $(\mathrm{N}=1,767)$

\begin{tabular}{lccccc}
\hline Digits & Ten Thousands (10,000) & Thousands (1,000) & Hundreds (100) & Tens (10) & Ones (1) \\
\hline 0 & 64.73 & 7.61 & 12.85 & 73.78 & 98.27 \\
1 & 24.11 & 9.91 & 2.59 & 0.00 & 0.00 \\
2 & 7.55 & 10.32 & 8.18 & 0.17 & 0.00 \\
3 & 1.27 & 11.99 & 4.96 & 0.00 & 0.06 \\
4 & 0.23 & 12.97 & 7.84 & 0.17 & 0.06 \\
5 & 0.12 & 10.84 & 20.81 & 6.51 & 0.23 \\
6 & 0.00 & 10.32 & 4.78 & 0.23 & 0.06 \\
7 & 0.00 & 9.97 & 5.13 & 0.23 & 0.00 \\
8 & 0.00 & 9.05 & 8.41 & 1.15 & 0.17 \\
9 & 0.00 & 7.03 & 100.44 & 17.75 & 1.15 \\
\hline Total & 100.00 & 100.00 & & 100.00 & 100.00 \\
\hline
\end{tabular}

This confirms that considering the used car price ending formats as the three rightmost digit of the price is pertinent. To complete this, we firstly analyze retailers and amateur sellers price ending formats separately and determine the most commonly price ending formats for each reseller's profile in line with RQ1. Secondly, we determine how car attributes and reseller's profiles can influence price ending formats adoption following RQ2.

\section{RESULTS}

\section{The Non-Uniformly Distribution of the Three Rightmost Digits}

To identify the most commonly observed prices, we split the sample by seller's profiles and compare digit distribution to the uniform distribution. A unilateral frequency test for uniform distribution is computed for each digit to define the mostly common price ending formats. Splitting the sample also supports a comparison of the digit distributions for each seller's type. It also provides strong evidence of their differentiated pricing behaviors, because the price ending tactics do not converge between the two profiles. However, the distribution of digits is very similar in the ten-thousands and thousands positions, even if most of the used car prices are less than 10,000 Euros, which explains the prevailing use of 0 in the leftmost position. The distribution of hundreds is more uniform in the professional sample than in the amateur sample. Amateur sellers concentrate largely on the hundred digit, which may be the one that is easiest for them to recall (Brenner \& Brenner, 1992; Folkertsma, 2002; Schindler \& Kirby, 1997). For example, the use of 4 is half as common among amateurs than among professionals $(4.96 \%$ vs. $10.71 \%)$. Furthermore, the descriptive statistics show a huge difference in the use of a 0 in the hundreds position: $22.7 \%$ among amateurs but only $3.0 \%$ for professional sellers. The 9 digit instead is more common for professionals: $38.7 \%$ vs. $10.2 \%$ for amateurs. That is, professionals use 9 , and the tactic is closely associated with professional retailers of new items. At the positions of the ten digits, very few digits get used. Despite this minimal divergence, professionals still use 9 approximately ten times as often as amateurs.

The results for the frequency test computed for the three rightmost digits allow defining the most common digits observed for each type of reseller.

Considering professional retailers, results show that digits " 5 " and "9" are significantly observed in the hundreds position, " 0 " and " 9 " in the tens position and " 0 " in the ones position. These mostly observed digits permits to define the mostly observed digit combinations for the three rightmost digits. So, four most commonly price ending formats can be defined for the professional car retailers: "500," "590," "900," and "990."

Considering amateurs, results show that digits " 5 " and "0" are significantly observed in the hundreds position, " 0 " in the tens and one's position. So, two most commonly price ending formats can be identified for the amateur car sellers: "500" and "000."

We see that price ending formats used by both resellers are differentiated. This supports the non-imitative strategy of amateurs in their pricing tactics. The non-uniformly distribution analysis of the three rightmost digits suggests the appropriateness of focusing the remainder of this investigation on the five most often used ending prices: "000," "500 \& 590," "900," and "990." These five forms appear in more than half of the sampled car ads. 
The following section addresses the methodology designed to explain price format adoption in used car redistribution in line with RQ2.

\section{MNL Specification and IIA Assumption}

To determine which factors have impact on sellers' decision to use price ending formats, this study next proposes a discrete choice model, in which sellers' pricing choices are discrete and exclusive (Hensher et al., 2005). The seller chooses among the five price ending formats or some other price ending (denoted tariff "X"). This seller should seek the pricing tactic that provides the maximum utility. In this scenario, the seller faces six discrete alternatives, which are exclusive and not ordered, so a multinomial logit (MNL) model is well suited for this analysis (Baltas \& Doyle, 2001). Such a model can explain choices using stochastic utility and the deterministic decision rules adopted by decision makers faced with several alternatives (McFadden, 1973, 1974).

The final MNL model includes 16 alternative specific independent variables, controlled for collinearity. The test for the IIA hypothesis also controls for the possibility that the ratios of the choice probabilities are not influenced by the number of alternatives. The results of the full model in Table 4 use tariff (0), i.e. tariff "X," as the reference price ending. According to the Hausman (1978) and Small and Hsiao (1985) tests for IIA, the five alternatives are relevant, and the choice probability ratios are not influenced by the number of alternatives. The overall goodness of fit of the model, measured by the R-square indicator, is acceptable (0.096) for this MNL specification. The likelihood ratio test also supports the overall significance of the model.

The coefficients indicate the impact of each variable on the ratio of probabilities of choosing any other price ending (tariff (1) = "000"; tariff (2) = "900"; tariff (3) = "500" \& " $590 "$ "; or tariff (4) = "990") rather than tariff (0) "X." Sixteen alternative specific independent variables in the model help explain sellers' choices of a particular price ending. The results thus suggest that some independent variables have significant, systematic effects on sellers' price-ending choices. Some of these significant variables provide new insights in relation with RQ2.

The model reveals a significant difference in individual amateurs' and professional dealers' adoption of pricing tactics. The sign and significance of the individual amateur seller variable confirms the differentiated use of the identified tariffs. These findings extend understanding of pricing in popular redistribution channels (Paden \& Stell, 2005). In accordance with level and image effects (Stiving \& Winer, 1997), the interpretations of the findings reveal how retailers of various types can use pricing formats to signal the market. Professionals use " 990 " and "900" ending prices significantly more than amateurs. Individual sellers instead are much more likely to use " 000 " ending prices and far less likely to use "900" and "990" ending prices. However, the results do not indicate a difference for the " 590 " and " 500 " tariffs. These results are consistent with extant marketing literature if " $900 "$ "and " 990 " are considered as a declination of the so called attractive "9-ending" prices. As a traditional tactic, 9-ending prices get applied exclusively by professional retailers as a low price appeal tactic. We can hypothesize that amateurs avoiding the use of such a tactic probably do so to differentiate their offer from a standard, professional strategy. Furthermore, the more intensive use of rounded prices helps probably amateurs signal the "good quality" characteristic of their offers (following Stiving \& Winer, 1997). But, we could interpret this good car quality as a way to create a sense of fairness because potential buyers are motivated in avoiding professional used car retailers. As we mentioned previously, buyers would consider professionals lack of honesty and unfair prices as sufficient sources of motivation for choosing "alternative" CtoC channel. Yet the use of "500" and "590" tariffs are not correlated to seller's profiles, this contributes to research that suggests the digit "5" is an easy number to remember (Macé, 2012; Ngobo, 2010; Folkertsma, 2002; Schindler \& Kirby, 1997).

The two interaction variables included in the model give new insights on price ending formats' adoption. The positive effect of a mileage up to $100,000 \mathrm{~km}$ on " 000 " tariff adoption is lower if the seller is an amateur. This means that amateur sellers are less sensitive to car kilometers than professionals when choosing tariff "000." Similarly, the positive effect of a high price level (up to 7,500 €) on "590" and " 500 " tariffs adoption is greater if the seller is an amateur. That is, amateurs are more sensitive to the expensiveness of the car when they set ending prices than professionals are. 
Table 4: MNL Estimation Results

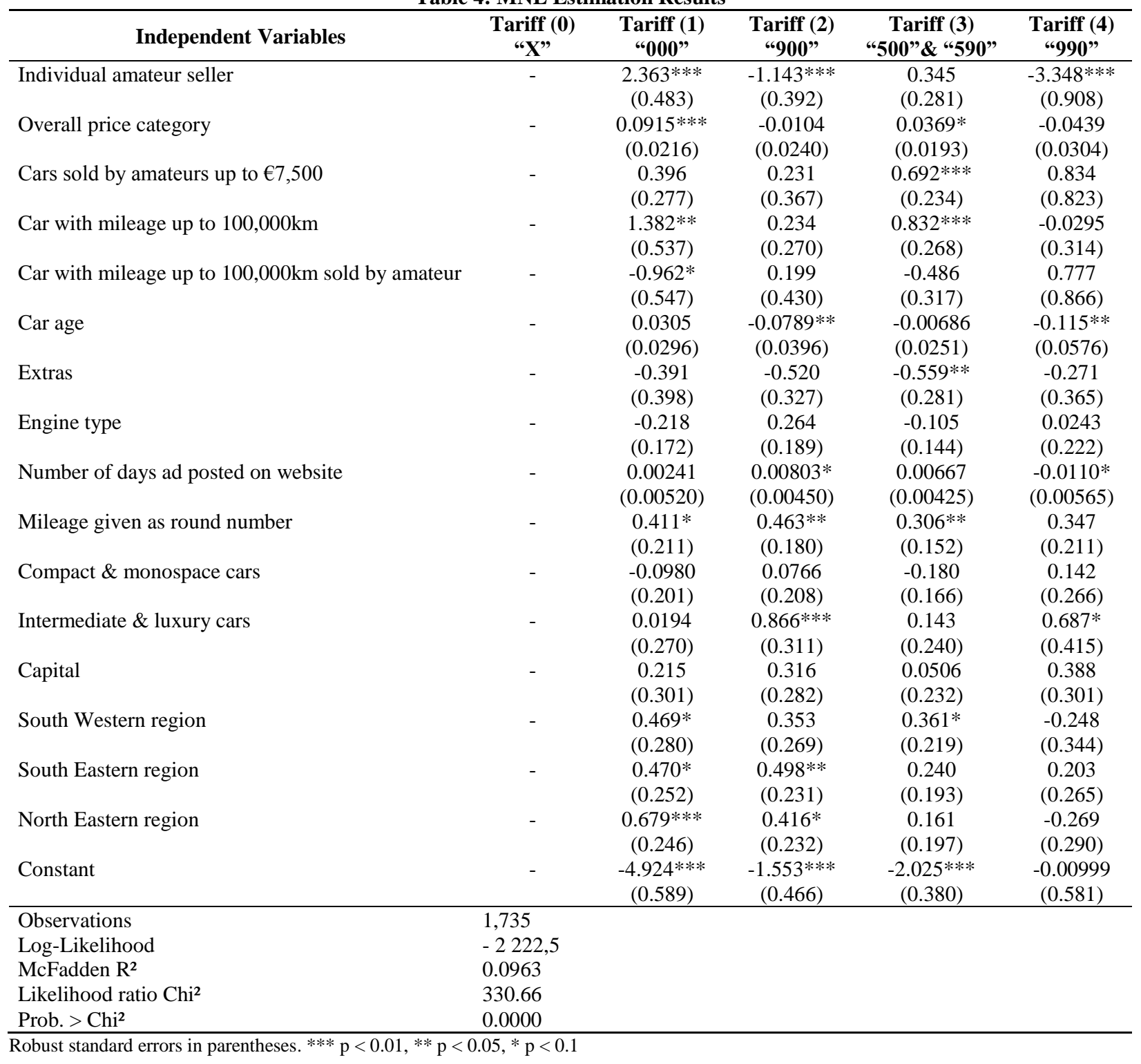

The car age variable appears significant only for "900" and "990" tariffs. That is, decrease in age exclusively raises the adoption of the " $900 "$ and " $990 "$ tariffs. Because younger cars are more homogeneous in their states, usages, and storage conditions than older cars, which makes them closed substitutes and induces intensive competition, sellers seek to differentiate their offer and increase price appeals using these formats. As car age also provides a good indicator of car obsolescence; it also offers a proxy for the price discount that likely is available for this used car, compared with an equivalent new car. For such a discount, signaling the item's low price appeal may be less pertinent for older cars. This remark holds if we assume " 900 " and "990" formats as 9-ending formats that could be used by resellers (here mainly professionals) for their recent used cars they want to signal the low price appeal (Stiving \& Winer, 1997). This result underlines the very important feature of obsolescence for determining not only value in a used market context as suggested by Holbrook (1999), but also for the adoption of price ending formats.

Round and "500 \& 590" ending prices instead correlate positively with future usages (low car kilometers). Similarly, the total kilometers accrued by the used car affect perceived obsolescence, in terms of the utility the used 
car can still provide. Following previous hedonic pricing research (Kooreman \& Haan, 2006), this variable appears in the model as a dummy, due to concerns about collinearity. Selling a car with up to $100,000 \mathrm{~km}$ significantly increases the probability of choosing tariffs " 000 " and " $500 \& 590$." These findings clarify the conditions in which car obsolescence affects price formats: Car age, as a proxy for the discount obtained from buying used as opposed to an equivalent new car, decreases adoption of ' 900 " and " 990 " tariffs, whereas total kilometers, as a proxy of future usage utility, increases the adoption of rounded and "500 \& 590" tariffs.

In this study though, extra options and fuel type that can be considered as proxies for car quality information provided to potential buyers are included as explanatory variables of price ending format adoption. The variable parameters for extra options (air conditioning, cruise control, and GPS) decrease significantly the probability of choosing "590 \& 500" tariff. As Verboven (2002b) argued, diesel engine cars should represent better quality than petrol-based cars. However the engine type parameter offer no evidence of a significant impact of diesel engine type on the adoption of price ending format. So, objective car quality indicators have no impact on price ending adoption except for the " $500 \& 590$ " tariff.

The model also includes indicators for the vertical differentiation of the European car market (Verboven, 2002a; Verboven \& Brenkers, 2006). Thus, the H segment of intermediate and luxury cars, should be of higher quality than the $\mathrm{C}$ segment of compact cars. These $\mathrm{C}$ segment cars in turn should be perceived as offering higher quality than the B segment. The intermediate and luxury cars have a positive impact on the adoption of the "900"and 990 " tariffs. So, this suggests that high quality used car sellers are more likely to use "900" and "990" tariffs than lower quality used car sellers. This result provides a new path on how quality could impact price ending adoption in the special case of used car transactions. This is not totally in line with previous literature. If rounded prices are preferable to 9-ending prices for higher priced goods and those goods associated with high quality (Stiving, 2000), the result obtained here invites to engage further investigation as this relation seems to be highly context related (new vs. used items, high vs. low involvement). Furthermore, as Akerlof (1970) highlighted, second-hand markets feature substantial information asymmetries related to quality that could probably lead to change the perceptions of identified price ending formats. Additionally, this asymmetry also suggests that quality cannot be inferred only by objective product attributes (Pauwels et al., 2007; Golder et al., 2012).

\section{CONCLUSION}

This study provides new insights of the context dependence of different price ending formats. This empirical investigation complements previous work because of the special case study: a high involvement, durable good in a used market context. Using the French used car market as a good illustration of traditional used item transactions, the explanatory study identifies the most commonly observed ending used car price formats defined on the three rightmost digits. The study confirms the non-uniformly distribution of these digits following Aalto-Setala and Halonen (2004) and provides information on reseller's behavior: Used car resellers do not practice the same tactics depending on professional or amateur's profiles. With this unique and original perspective, it also identifies how price ending adoption is influenced by used car attributes as well as by sellers' profile.

The results may also suggest that while price ending associations might be socially acquired (Schindler, 2006) - e.g. that 9-endings prices reflect lower prices and thus attract more attention - these learnings seem to not be translated into the sales practices of individual amateurs (if " 900 " and "990" are assumed as 9 ending prices). An alternative explanation for this finding is that 9 ending prices may also be associated with lower product quality which leads to individual sellers' reluctance to use such price ending tactics. The reason for this could be that they feel personally involved with their old car and may not see (or may not want to see) the shortcomings of it. Whichever explanation holds, these findings provide an interesting insight into the dynamics of high involvement products via the internet. While consumers are generally seen as being more empowered through the internet (Rajamma et al., 2007, Grewal et al., 2003), as with wider product choice and greater price transparency bargaining power increases, this is one of the first studies to uncover how consumers act as sellers in online contexts. Our findings suggest that while this platform enables consumers to sell their belongings, it does not seem to be the case that they have yet adapted selling strategies of professionals. Future research should thus investigate in more detail how in such scenarios individual amateur sellers can effectively compete against professional sellers. 
These findings could be useful for professional used car retailers that are searching paths of growth in their used car business. This growth strategy is particularly targeted in the recent context of automobile crisis (CCFA, 2012). They could determine how price endings tend to be set to differentiate their pricing tactics from those of amateur sellers. They should be interested in setting rounded prices instead of 9-endings to signal for price fairness that could be in line with one of the motivations of used item purchasers: make a good deal. But they also should take into account the used car they are selling and, for example, avoid rounded prices if obsolete and old. Obviously, the results also contribute to retailers' understanding on tactics adopted by consumers who try to sell their used car on their own. This could help them to bargain new car prices when sales are conditioned by a trade-off (i.e. professional retailer have to buy the previous car owned by the consumer).

This study is subject to several limitations that suggest directions for further research. Firstly, as empirical work is based only on the French used car market, this doesn't allow generalizing the interpretations. Therefore, additional research is needed to establish the generalizability of the findings, as well as to determine whether the French used car market offers a good illustration of pricing tactics in a durable goods setting. Further research also could consider more brands and products, to provide a more detailed analysis of how brand and product quality affect the adoption of various price ending formats.

Secondly, we assume in the interpretations that amateur sellers could be influenced in their pricing by personal involvement. This question should be addressed in a qualitative study that could identify in what sense amateur sellers defined their pricing tactics and if they do this according to competition with professional retailers.

Finally, the study focuses on resellers' decisions about price endings, rather than investigating consumers' perceptions of these price ending formats. Empirical studies on consumers' perceptions of ending prices in a used item context could reveal exactly how they interpret rounded prices set by amateurs and why this price tactic appears to invoke perceptions of a good deal in second-hand markets. Specifically, we should investigate if price ending formats are perceived similarly by consumers if items are new or used.

\section{ACKNOWLEDGMENTS}

The author gratefully acknowledges Professor Neil Towers for providing his comments at the EIRASS conference in Vienna on an earlier version of the paper. He also thanks Professor Barbara Caemmerer and two anonymous reviewers from the 2012 EMAC conference for their helpful comments and suggestions.

\section{AUTHOR INFORMATION}

Marc Prieto is an Associate Professor of economics at the ESSCA Retail \& Services Automotive Chair. His research focuses on economics and consumer behaviour applied to the automobile industry and retail sector. He has worked for several years in the Department of Economics at the University of Rouen, France, where he also earned his $\mathrm{PhD}$. He discovered his interest for research applied to the automobile industry during his MA degree in industrial economics at the University of Paris 1 Panthéon Sorbonne. Some of his marketing projects in relation to the automobile sector include the branding and positioning retro cars, used car prices, attractive pricing tactics. E-mail: marc.prieto@essca.fr

\section{REFERENCES}

1. Aalto-Setala, V., \& Halonen, M. (2004). Attractive prices in grocery and automobile markets: Why is such pricing used? Journal of Retailing and Consumer Services, 299-306.

2. $\quad$ Akerlof, G. (1970). The market for "lemons." Quarterly Journal of Economics, 84(3), 488-500.

3. Anderson, E. T., \& Simester, D. I. (2003). Effects of $\$ 9$ price endings on retail sales: Evidence from field experiments. Quantitative Marketing and Economics, 1, 93-110.

4. Bader, L., \& Weinland, J. D. (1932). Do odd prices earn money? Journal of Retailing, 8, 102-104.

5. Baltas, G., \& Doyle, P. (2001). Random utility models in marketing research: A survey. Journal of Business Research, 51(2), 115-125. 
6. Boyd, T. C., \& McConocha, D. M. (1996). Consumer household materials and logistic management: Inventory ownership cycle. Journal of Consumer Affairs, 30(1), 218-230.

7. Bray, J. P., \& Harris, C. (2006). The effect of 9-ending prices on retail sales: A quantitative UK based field study. Journal of Marketing Management, 22, 601-617.

8. Brenner, G. A., \& Brenner, R. (1982). Memory and markets, or why are you paying $\$ 2.99$ for a wiget? Journal of Business Research, 55, 147-158.

9. Folkertsma, C. K. (2002). The Euro and psychological prices: Simulations of the worst-case scenario. De Economist, 150(1), 19-40.

10. French Automakers Committee (CCFA). (2012). Report on automotive data 2011. Paris.

11. Golder, P. N., Debanjan, M., \& Moorman, C. (2012). What is quality? An integrative framework of processes and states. Journal of Marketing, 76(July), 1-23.

12. Grewal, D., Munger, J., Iyer, G., \& Levy, M. (2003). The influence of internet-retailing factors on price expectations. Psychology \& Marketing, 20(6), 477-493.

13. Grover, S. L., \& Enz, C. A. (2005). The influence of company rules, ethical climate and individual characteristics on sales representative honesty. Journal of Autralian and New Zealand Management, 11(2), 27-36.

14. Harell, G. D., \& McConocha, D. M. (1992). Personal factors related to consumer product disposal tendencies. Journal of Consumer Affairs, 26(2), 397-417.

15. Hausman, J., \& McFadden, D. (1984). Specification tests for the Multinomial Logit model. Econometrica, 52(5), 1219-1240.

16. Hawkins, D. I., Best, R. J., \& Coney, K. A. (2004). Consumer behavior: Building marketing strategy. Boston, MA: McGraw Hill.

17. Hensher, D. A., Rose, J. M., \& Greene, W. (2005). Applied choice analysis. Cambridge: Cambridge University Press.

18. Holbrook, M. B. (1999). Consumer value. A framework for analysis and research. London: Routledge.

19. Jacoby J., Berning C. K., \& Dietvorst T. F. (1977). What about disposition? Journal of Marketing, 41(April), 22-28.

20. Kooreman, P., \& Haan, M. A. (2006). Price anomalies in the used car market. De Economist, 154(1), 4162.

21. Macé, S. (2012). The impact and determinants of nine-ending pricing in grocery retailing. Journal of Retailing, 88(1), 115-130.

22. Manning, K. C., \& Sprott, D. E. (2009). Price endings, left digits effects, and choice. Journal of Consumer Research, 36(August), 328-335.

23. McFadden, D. (1973). Conditional logit analysis of qualitative choice behavior. In P. Zarembka (Ed.), Frontiers of econometrics (pp. 105-142). New York Academy Press.

24. McFadden, D. (1974). Conditional logit analysis of qualitative choice behavior. In Z. Griliches, Handbook of econometrics M.D. Intriligator, Vol. 2 (pp. 1395-1457). Amsterdam.

25. Milgrom, P., \& Roberts, J. (1986). Pricing and advertising signals of product quality. Journal of Political Economy, 94, 796-821.

26. Nagle, T. T., Hogan, J. E., \& Zale, J. (2011). The strategy and tactics of pricing: a guide to provide more profitability. New Jersey: Pearson Education.

27. Ngobo, P. V., Legohérel, P., \& Guéguen, N. (2010). A cross country investigation into the effects of nineending pricing on brand choice. Journal of Retailing and Consumer Services, 17, 374-385.

28. Nguyen, A., Heeler, R. M., \& Taran, Z. (2007). High-low context cultura and Price-ending practices. Journal of Product and Brand Management, 16(3), 206-214.

29. Paden, N., \& Stell, R. (2005). Consumer product redistribution: Disposition decision and channel options. Journal of Marketing Channels, 12(3), 105-123.

30. Pauwels, K., Srinivasan, S., \& Franses, P. H. (2007). When do price thresholds matter in retail categories? Marketing Science, 26(1), 83-100.

31. Rajamma, R., Paswan, A., \& Ganesh, G. (2007). Services purchased at brick and mortar versus online stores, and shopping motivation. Journal of Services Marketing, 21(3), 200-212.

32. Roux, D., \& Guiot, D. (2008). Measuring second-hand shopping motives, antecedents and consequences. Recherche et Applications en Marketing, 23(4), 63-94.

33. Rudolph, H. J. (1954). Pricing for today's market. Printers'Ink, 247, 22-24. 
34. Schindler, R. (2011). Pricing strategies. Sage Publications.

35. Schindler, R. (2006). The 99 price ending as a signal of a low-price appeal. Journal of Retailing, 82(1), 7177.

36. Schindler, R., \& Kirby, P. (1997). Patterns of rightmost digits used in advertised prices: Implications for nine-ending effects. Journal of Consumer Research, 24(September), 192-201.

37. Schindler, R., \& Kibarian, T. M. (1996). Increased consumer sales response though use of 99-ending prices. Journal of Retailing, 72(2), 187-199.

38. Small, K. A., \& Hsiao, C. H. (1985). Multinomial logit specification tests. International Economic Review, 26(3), 619-627.

39. Spence, M. (1973). Job market signaling. The Quarterly Journal of Economics, 87(3), 355-374.

40. Stiving, M. (2000). Price endings: When prices signal quality. Management Science, 46(December), 16171629.

41. Stiving, M., \& Winer, R. S. (1997). An empirical analysis of price ending using scanner data. Journal of Consumer Research, 24(June), 57-67.

42. Thend Tracker. (2009). The future of the used car market. Report. Retrieved July 2013 from http://www.trendtracker.co.uk/store/2009/06/the-future-of-the-used-car-market-in-great-britain-2009--2014

43. Twedt, D. W. (1965). Does the 9' fixation in retail pricing really promote sales? Journal of Marketing, 29(October), 54-55.

44. Verboven, F., \& Brenkers, R. (2006). Market definition with differentiated products: Lessons from the car market. In J. P. Choi (Ed.), Recent developments in antitrust: Theory and evidence. Cambridge: MIT Press.

45. Verboven, F. (2002a). Quantitative study to define the relevant market in the passenger car sector. Report for the European Commission for competition.

46. Verboven, F. (2002b). Quality-based price discrimination and tax incidence: Evidence from gasoline and diesel cars. RAND Journal of Economics, 33(2), 275-297.

47. Wagner, R., \& Beinke, K. S. (2006). Identifying patterns of customer response to price endings. Journal of Product and Brand Management, 15(5), 341-351.

48. Williams, C., \& Paddock, C. (2003). The meanings of informal and second-hand retail channels: Some evidence from Leicester. The International Review of Retail, Distribution and Consumer Research, 13(3), 317-336.

49. Wood, J. A., Boles, J., S., Johnston, W., \& Bellenger, D. (2008). Buyers' trust of the salesperson: An itemlevel meta analysis. Journal of Personal Selling and Sales Management, 28(3), 263-283.

50. Yin, S., Ray, S., Gurnani, H., \& Animesh, A. (2010). Durable products with multiple used goods markets: Product upgrade and retail pricing implications. Marketing Science, 29(3), 540-560. 